Volume 4 Nomor 2, Juli-Desember 2020: hlm. 143-156.

Fakultas Hukum, Universitas Lampung,

Bandar Lampung, Lampung, Indonesia.

E-ISSN: 2598-3105 P-ISSN: 2723-2581

http://jurnal.fh.unila.ac.id/index.php/cepalo

(ㅇ) (1) CEPALO

\title{
PELAYANAN YANG DITERIMA OLEH MASYARAKAT SEBAGAI PEMBAYAR PAJAK BERDASARKAN PENERAPAN BEBAN PAJAK DAERAH YANG DIATUR DALAM UNDANG-UNDANG PAJAK DAN RETRIBUSI DAERAH
}

\author{
SERVICES RECEIVED BY THE COMMUNITY AS TAXPAYERS BASED ON \\ APPLICATION OF REGIONAL TAX EXPENSES REGULATED IN LAW OF THE \\ REPUBLIC INDONESIA NUMBER 28 YEAR 2009 CONCERNING LOCAL TAXES \\ AND CHARGES
}

\section{Salsabila Aufadhia Ilanoputri}

Fakultas Hukum, Universitas Indonesia, Email: salsabilaaufadhia@gmail.com

Submitted: July 9, 2020; Reviewed: July 28, 2020; Accepted: August 10, 2020

DOI: $10.25041 /$ cepalo.v4no2.2067

\begin{abstract}
Abstrak
Pajak merupakan instrumen perekonomian yang menjadi sumber pemasukan utama sebuah negara dan merupakan kewajiban setiap warga negara yang diatur dalam UUD NRI 1945. Pajak di Indonesia sendiri menurut kewenangannya terbagi menjadi pajak pusat dan daerah. Pajak sebagai penopang penerimaan daerah menjadi tidak optimal apabila regulasi dan kebijakan yang dibuat oleh pemerintah daerah tumpah tindih dengan kebijakan perpajakan nasional. Dari sisi masyarakat, rasio penerimaan retribusi daerah lebih tinggi dibandingkan dengan rasio penerimaan pajak daerah tersebut dikarenakan masyarakat menghendaki adanya pelayanan sehingga pemerintah harus memberikan standar parameter pelayanan bagi masyarakat atas kontribusinya dalam pembayaran pajak. Pemerintah diharapkan dapat memberikan pelayanan yang sepadan kepada masyarakat sebagai pembayar pajak agar masyarakat dapat merasakan manfaat atas pembayarannya. Berdasarkan hal tersebut maka perumusan masalah yang akan dibahas ialah bagaimana standar pelayanan pajak daerah di Indonesia? dan bagaimana keseimbangan beban pajak daerah dengan pelayanan yang diberikan kepada masyarakat? Penulisan ini untuk mengetahui keseimbangan beban pajak daerah dengan pelayanan yang diberikan kepada masyarakat. Jenis penelitian yang akan digunakan adalah penelitian normatif dengan menggunakan data sekunder. Pengolahan data dilakukan dengan cara melakukan sistematika terhadap bahan-bahan hukum tertulis dan studi kepustakaan. Hasil menunjukkan bahwa pelayanan yang diberikan kepada masyarakat dari penerimaan pajak daerah dapat diukur melalui dua parameter sebagai bentuk kontraprestasi bagi sektor pajak yang dipungut yakni parameter formal dan parameter ideal. Kontrapretasi tersebut harus sesuai dengan peruntukannya dan ditentukan dalam undang-undang maupun peraturan pelaksanannya.
\end{abstract}

Kata Kunci: Beban, Daerah, Pajak, Pelayanan. 


\section{Abstract}

Tax as an economic instrument which is the main souce of income for a country and is the obligation of every citizen as regulated in the 1945 Constitution of the Republic of Indonesia. Taxes in Indonesia are divided into central and regional taxes according to their authority. Taxes as a support for regional revenues are not optimal if regulations and policies made by local governments overlap with national tax policies. From the community perspective, the ratio of local retribution revenue is higher than the ratio of local tax revenue because the community wants proper service so that the government must provide standard service parameters for the community for its contribution in paying taxes. The government is expected to be able to provide services that are equivalent to the public as taxpayers so that people can feel benefit from the payment. Based on this, the problem to be discussed are how the standard of local tax services in Indonesia? and how to balance the local tax burden with the services provided to community? This writing is to determine the balance of the regional tax burden with the services provided to the community. This type of research uses normative research by using secondary data. The data collection method is carried out by systematically applying written legal materials and literatures. The result show that the services provided to the community from local tax revenues can be measured through two parameters as a form of counter achievement for tax levied sector, there are formal parameters and ideal parameters. The contradiction must be in accordance with its designation and specified in the law and its implementing regulations.

Keywords: Expense, Local, Services, Tax.

\section{A. Pendahuluan}

Kegiatan pembangunan merupakan suatu proses kegiatan yang dilakukan dalam agenda mengembangkan atau membuat suatu perbedaan keadaan yang mencerminkan keadaan yang lebih baik. Pembangunan yang berusaha diwujudkan oleh rakyat Indonesia adalah tercapai dan terwujudnya masyarakat yang adil dan sejahtera dalam aspek materiel dan spiritual berdasarkan falsafah dasar yaitu Pancasila serta Undang-Undang Dasar 1945. Semua itu di lakukan untuk mencapai kegiatan pembangunan nasional yang baik dan mensejahterakan, dalam penyusunan dan pembentukan program pembangunan tersebut pemerintah mengikuti pola-pola tertentu atau mekanisme yang telah ditentukan di dalam pemerintah negara Indonesia. Negara dalam menjalankan pemerintahan memerlukan biaya yang sangat besar. Pajak yang termasuk kedalam sumber penerimaan negara terbesar pernah dilaksanakan adanya reformasi pajak. Reformasi pajak yang ditujukan untuk mencapai target dan sasaran yang tepat. Tentunya reformasi dibidang pajak telah memperhatikan adanya aspek keadilan, dan mempertimbangkan mengenai daya saing ekonomi yang ada di lingkup nasional maupun internasional. ${ }^{1}$

Pemerintah pusat membentuk suatu kebijakan yang mana pemerintah daerah diberikan otoritas guna mengelola dan mengatur keuangan daerah masing-masing. Konsep ini bisa lebih dikenali dengan konsep desentralisasi. Semua hal tersebut dilakukan dengan harapan daerah akan memiliki kemampuan untuk berkembang dalam hal pembangunan daerah. Tentunya pembangunan daerah tersebut harus sesuai prinsip daerah otonom yang sebenarnya. Konsep otonomi daerah yang merupakan bagian dari konsep desentralisasi memiliki tujuan untuk memberikan ruang yang lebih luas untuk daerah dalam memperluas cakupan dalam segi pendanaan dalam agenda pelaksanaan pembangunan daerah. Otonomi daerah bisa digunakan sebagai sarana untuk semakin meningkatkan Pendapatan Asli Daerah, pemerintah daerah

\footnotetext{
${ }^{1}$ Fuad Bawazier, "REFORMASI PAJAK DI INDONESIa," Jurnal Legislasi Indonesia 8, no. 1 (2018): 1-12, 1.
} 
harus terus berupaya agar bisa memaksimalkan adanya sumber-sumber dana yang dapat menjadi pendapatan di wilayah, serta memaksimalkan adanya potensi untuk diambil pajak dan retribusi. ${ }^{2}$

Pendapatan Asli Daerah merupakan salah satu sumber dana yang diterima oleh daerah yang mempunyai fungsi dan peran penting dalam pembangunan. Pendapatan Asli Daerah (PAD) ialah sumber pendapatan daerah yang dalam hal ini masuk dalam kategori bebas dapat diperuntukan oleh masing-masing daerah dalam rangka menjalankan dan membantuk roda pemerintahan dan pembangunan di suatu daerah. Usaha dalam meningkatan PAD ialah dengan memaksimalkan adanya proses efesiensi sumber daya dan alat kelengkapan yang sangat terbatas dan melakukan upaya untuk naik dalam hal efektifitas pengambilan dengan upaya melaksanakan adanya pengoptimalan potensi yang ada dan selalu mengupayakan dan menggali sumber pendapatan yang baru dengan pertimbangan memiliki potensi, semua hal tersebut dimungkinkan sehingga dapat diambil pajak dan retribusinya. ${ }^{3}$

Berdasarkan sudut pandang fiskal, selain adanya PAD. Pajak merupakan penerimaan negara yang menghimpun dana masyarakat melalui mekanisme yang diatur oleh peraturan perundang-undnagan demi kesejahteraan masyarakat. ${ }^{4}$ Pajak merupakan sumber yang sangat penting bagi pendapatan negara dalam menyelenggarakan pemerintahan dan pelaksanaan pembangunan nasional. Kewajiban perpajakan dijadikan sarana pembiayaan negara dalam pembangunan nasional untuk mencapai tujuan negara. ${ }^{5}$ Menurut Undang-Undang Nomor 28 Tahun 2007 tentang Ketentuan Umum dan Tata Cara Perpajakan (selanjutnya disebut UU KUP), pajak adalah kontribusi wajib kepada negara yang bersifat memaksa untuk kemudian digunakan bagi keperluan negara dalam memberikan rakyat kemakmuran. ${ }^{6}$ Hal tersebut juga bersesuaian dengan apa yang diamanatkan Undang-Undang Dasar Negara Republik Indonesia Tahun 1945 (selanjutnya disebut UUD NRI 1945) yakni pajak merupakan kewajiban bernegara. Kewajiban membayar pajak sendiri tercantum dalam Pasal 23A UUD NRI 1945 dimana hal tersebut diatur oleh undang-undang dan bersifat memaksa untuk keperluan negara. ${ }^{7}$ Pajak sebagai instrumen perekonomian merupakan sumber pemasukan utama sebuah negara dan merupakan kewajiban setiap warga negara yang diatur dalam UUD NRI 1945. Di Indonesia, pajak memiliki posisi yang penting sebagai penopang terbesar Anggaran Pendapatan dan Belanja Negara (APBN) di negara Indonesia. ${ }^{8}$

\footnotetext{
${ }^{2}$ Heince R. Wokas and Rezlyanti Kobandaha, "ANALISIS EFEKTIVITAS, KONTRIBUSI DAN POTENSI PAJAK REKLAME DAN PAJAK HOTEL TERHADAP PENDAPATAN ASLI DAERAH KOTA KOTAMOBAGU," Jurnal Riset Ekonomi, Manajemen, Bisnis dan Akuntansi 4, no. 1 (2016): 1461-1472, 1462, DOI: 10.35794/emba.v4i1.12366.

3 Alfan A. Lamia, David P.E. Saerang, and Heince R.N Wokas, "ANALISIS EFEKTIFITAS DAN KONTRIBUSI PEMUNGUTAN THE ANALYSIS OF EFECTIVENESS AND CONTRIBUTION RECEIPTS TAX RESTAURANT, ADVERTISING TAX AND STREET LIGHTING LEVY DISTRIct," Jurnal Berkala Ilmiah Efisiensi 15, no. 05 (2015): 788-799, 789.

${ }^{4}$ Rizka Novianti Pertiwi, Devi Farah Azizah dan Bondan Catur Kurniawan, "ANALISIS EFEKTIVITAS PEMUNGUTAN PAJAK BUMI DAN BANGUNAN (STUDI PADA DINAS PENDAPATAN, PENGELOLAAN KEUANGAN DAN ASET KOTA PROBOLINGGO)", Jurnal Perpajakan 3, no. 1 (2014): 17,1 .

${ }^{5}$ Dwi Sulastyawati, "HUKUM PAJAK DAN IMPLEMENTASINYA BAGI KESEJAHTERAAN RAKYAT", Jurnal Filsafat dan Budaya Hukum 1, no. 1 (2014): 119-128, 120, DOI: 10.15408/sjsbs.v1i1.1530.

${ }^{6}$ Adi Suliantoro, "KAJIAN TERHADAP UU NO. 28 TAHUN 2007 TENTANG KETENTUAN UMUM DAN TATA CARA PERPAJAKAN", Fokus Ekonomi (FE) 7, no. 1 (2008): 36-43, 37.

${ }^{7}$ Dyah Adriantini Sintha Dewi, "IMPLEMENTASI PASAL 23 A UUD NEGARA REPUBLIK INDONESIA DALAM PENGEMBALIAN KELEBIHAN PEMBAYARAN PAJAK”, Jurnal Fakultas Hukum Universitas Muhammadiyah Magelang 4, no. 2 (2011): 1-19, 1.

8 https://www.pajakku.com/read/5d9ee689b01c4b456747b6d2/Pajak-dari-oleh-dan-untuk-Rakyat, diakses 29 Maret 2020.
} 
Pajak pusat adalah pajak yang dikelola oleh pemerintah pusat dalam hal ini Direktorat Jenderal Pajak untuk membiayai pengeluaran rutin negara dan pembangunan (APBN). ${ }^{9}$ Pajak pemerintah atau pajak pusat terdiri dari Pajak Pertambahan Nilai (PPN), PBB Perhutanan, Pajak Penghasilan (PPH), PBB Perkebunan, dan bea materai. ${ }^{10}$ Pungutan pajak daerah yang merupakan bagian dari Pendapatan Asli Daerah (PAD) memberikan peluang pada tiap daerah untuk melaksanakan pungutan pajak secara maksimal dan sebagai indikator kemandirian suatu daerah. ${ }^{11}$ Hal tersebut dapat disebabkan oleh beberapa faktor seperti potensi pungutan pajak daerah mempunyai sifat dan karakteristik yang jelas, secara teoritis, kebijakan, maupun dalam tataran implementasinya. ${ }^{12}$

Dalam pelaksanaan fungsi negara atau pemerintahan, pajak daerah berperan dalam fungsi mengatur (regulatory), penerimaan (budgetory), redistribusi (redistributive) dan alokasi sumber daya (resource allocation) maupun gabungan diantara keempatnya. Terdapat dua fungsi utama yang dibedakan dalam pajak daerah yakni fungsi budgetary dan fungsi regulatory. ${ }^{13}$ Pungutan pajak daerah bertujuan untuk meningkatkan pendapatan daerah di era otonomi daerah dimana kebutuhan dana dalam pelaksanaan tugas-tugas pemerintahan dan pembangunan daerah cukup besar disaat sumber-sumber pendanaan yang tersedia masih terbatas. ${ }^{14}$ Pajak daerah memberikan sebagai salah satu komponen penerimaan PAD, memberikan peluang bagi daerah untuk melaksanakan pungutan pajak secara maksimal sehingga menjadi salah satu komponen terbesar penerimaan PAD jika dibandingkan dengan komponen-komponen lainnya. ${ }^{15}$ Penerimaan pajak daerah akan optimal apabila pemerintah daerah membuat regulasi dan kebijakan yang selaras dengan kebijakan perpajakan nasional agar tidak menjadi beban bagi daerah maupun nasional. ${ }^{16}$

Seiring dengan perubahan tata kelola pemerintahan di Indonesia menjadi otonomi daerah sejak ditetapkannya Undang-Undang Nomor 22 Tahun 1999 tentang Pemerintahan Daerah (sebagaimana telah diganti dengan Undang-Undang Nomor 23 Tahun 2014 tentang Pemerintahan Daerah dan terakhir diubah dengan Undang-Undang Nomor 9 Tahun 2015), pemerintah akan lebih memberikan pelayanan kepada masyarakat lokal melalui pemerintah daerah. ${ }^{17}$ Merujuk pada teori welfare state bahwa negara Indonesia dibentuk sebagai negara kesejahteraan sebagaimana tercantum dalam Alinea Kedua Penjelasan UUD NRI 1945 dan teori kemanfaatan berkaitan pengelolaan pajak pemanfaatannya harus diupayakan untuk pelayanan kepada sektor pajak yang bersangkutan. ${ }^{18}$ Dengan demikian, masyarakat mengkehendaki adanya pelayanan yang diberikan pemerintah kepada rakyat yang dibiayai pajak. ${ }^{19}$ Dari sisi masyarakat, perbandingan antara penerimaan retribusi daerah lebih tinggi

\footnotetext{
${ }^{9}$ https://bprd.jakarta.go.id/2016/10/10/pajak-daerah-bukan-pajak-pusat/, diakses 29 Maret 2020.

${ }^{10}$ Sentosa Siahaan, Albert Lodewyk. "KAJIANYURIDIS TERHADAP BERALIHNYA KEWENANGAN PEMUNGUTAN PAJAK BUMI DAN BANGUNAN PERDESAAN DAN PERKOTAAN DARI PEMERINTAH PUSAT KEPADA PEMERINTAH DAERAH KABUPATEN SERDANG BEDAGAI", Premise Law Journal 8, (2015): 1-16, 2.

11 Dewi Oktavina, "ANALISIS PENDAPATAN ASLI DAERAH DAN FAKTOR-FAKTOR YANG MEMPENGARUHINYA DALAM RANGKA OTONOMI DAERAH: PENDEKATAN ERROR CORRECTION MODEL", JEPE: Jurnal Ekonomi Pembangunan 10, no. 2 (2012): 89-101, 89, DOI:10.22219/jep.v10i2.3720.

${ }^{12}$ http://www.djpk.kemenkeu.go.id/wp-content/uploads/2018/08/pajak_daerah-1.pdf, diakses 29 Maret 2020.

${ }^{13}$ F.C. Susila Adiyanta, "KARAKTERISTIK RESPONSIF PERATURAN DAERAH TENTANG PAJAKPAJAK DAERAH SEBAGAI REPRESENTASI DAN PARTISIPASI KEHENDAK PUBLIK”, Administrative Law \& Governance Journal 2, no. 2 (2019): 380-399, 385, DOI: 10.14710/alj.v2i3.380\%20-\%20399.

${ }^{14} \mathrm{http}: / /$ www.djpk.kemenkeu.go.id/wp-content/uploads/2018/08/pajak_daerah-1.pdf, diakses 29 Maret 2020.

${ }^{15}$ F.C. Susila Adiyanta, Op.Cit., 382.

${ }^{16}$ Ibid.

${ }^{17}$ Tjip Ismail, Potret Pajak Daerah di Indonesia (Jakarta: Prenadamedia Group, 2018), 46.

${ }^{18}$ Ibid., 28-36

${ }^{19}$ Ibid., 46
} 
dibandingkan penerimaan pajak daerah dikarenakan masyarakat menghendaki adanya pelayanan. Dapat dikatakan bahwa masyarakat akan membayar retribusi secara sukarela meskipun besar apabila pelayanan yang diberikan oleh pemerintah daerah ditingkatkan. ${ }^{20}$

Oleh karena itu, mengingat potensi penerimaan penerimaan pajak daerah cukup besar maka pemerintah diharapkan juga dapat memberikan pelayanan yang sepadan kepada masyarakat yang membayar pajak. Apabila pembayar pajak merasakan manfaat atas pembayarannya, maka akan timbul kesadaran untuk melakukan pembayaran pajak. Berdasarkan hal tersebut maka perumusan masalah yang akan dibahas ialah bagaimana standar pelayanan pajak daerah di Indonesia? dan bagaimana keseimbangan beban pajak daerah dengan pelayanan yang diberikan kepada masyarakat?

Metode penelitian yang akan digunakan adalah penelitian hukum normatif yang juga disebut sebagai penelitian perpustakaan atau studi dokumen karena dilakukan hanya pada peraturan-peraturan yang tertulis atau bahan-bahan hukum yang lain. ${ }^{21}$ Pengolahan data akan dilakukan dengan menyusun bahan-bahan hukum tertulis yang digunakan secara sistematis. Analisis data penelitian hukum normatif pada bahan hukum primer dilakukan dengan cara yang diperoleh secara deskriptif kualitatif yaitu menganalisa terhadap data yang tidak bisa dihitung. Kemudian bahan hukum yang diperoleh akan diolah menjadi data informasi dengan membahas, memeriksa dan mengelompokkannya ke dalam bagian-bagian tertentu. Intepretasi hukum yang digunakan dalam penelitian akan menggunakan bahan hukum primer dan sekunder. Bahan hukum primer merupakan bahan hukum yang mengikat, terdiri dari norma dasar, peraturan dasar, peraturan perundang-undangan, yurisprudensi, dan traktat. ${ }^{22}$ Bahan hukum sekunder berupa semua publikasi tentanghukum meliputi buku-buku teks, kamuskamus hukum, jurnal-jurnal hukum, dan komentar-komentar atas putusan pengadilan. ${ }^{23}$

\section{B. Pembahasan}

\section{Standar Pelayanan Pajak Daerah}

Good governance merupakan konsep yang muncul akibat adnaya ketidakpuasan pada cara kerja serta kinerja pemerintahan yang pada saat yang lalu bisa dipercaya sebagai penyelenggara urusan publik tetapi mengalami kemunduran pada saat ini. ${ }^{24}$ Mengimplementasikan adanya praktik dari konsep good governance dapat dilakukan secara perlahan, melalui banyak tahap yang dikonstruksikan sesuai dengan kapasitas pemerintah, masyarakat sipil, dan mekanisme pasar. Pilihan yang menjadi opsi strategis untuk menerapkan good governance di Indonesia adalah melalui penyelenggaraan pelayanan publik. Pelayanan publik menjadi indikator adanya indeks keberhasilan pelaksanaan tugas dan perkembangan kerja dari pemerintah melalui mekanisme birokrasi.

Pelayanan publik sebagai mesin penggerak utama juga dirasa memiliki kedudukan yang penting oleh semua aktor dari unsur pelaksanaan dari konsep good governance. Pejabat yang berkaitan dengan publik, unsur-unsur dalam masyarakat biasa dan dunia Internasional memiliki tujuan dan upaya yang sama-sama memiliki kepentingan terhadap perbaikan kinerja pelayanan publik. Terdapat beberapa alasan penting mengenai urgensi adanya pelayanan publik dengan konsep good governance. Ada tiga urgensi utama yang sangat penting bahwa

\footnotetext{
20 Ibid.

${ }^{21}$ Soerjono Soekanto dan Sri Mamudji, Penelitian Hukum Normatif, Cet. Ke-8 (Jakarta: Raja Grafindo Persada, 2004), 14.

${ }^{22}$ Soerjono Soekanto dan Sri Mamudji, Penelitian Hukum Normatif: Suatu Tinjauan Singkat (Jakarta: Radja Grafindo Persada, 2001), 13.

${ }^{23}$ Peter Mahmud Marzuki, Penelitian Hukum (Jakarta: Kencana Prenada Media Group, 2008), 12.

${ }^{24}$ Neneng Siti Maryam, "MEWUJUDKAN GOOD GOVERNANCE MELALUI PELAYANAN PUBLIK," Jurnal Ilmu Politik dan Komunikasi 5, no.1 (2017): 1-18, 2.
} 
kegiatan pembaharuan pelayanan publik dapat menstimulan adanya praktik good governance atau birokrasi yang baik di Indonesia. Pertama, rekonsturksi ulang dari kinerja pelayanan publik dinilai penting bagi para pihak terkait atau stakeholders, yaitu pemerintah, warga, dan sektor usaha. Kedua. Pelayanan publik memiliki wilayah atau ruang lingkup dari ketiga unsur governance agat bisa melakukan hubungan timbal balik yang sangat intensif. Ketiga, bebrapa nilai-nilai yang terdapat didalam konsep good governance selama ini memiliki karakteristik praktik good governance diterjemahkan secara lebih mudah dan nyata melalui pelayanan publik. ${ }^{25}$

Pelayanan publik merupakan perwujudan tugas dan fungsi aparatur pemerintah untuk menyelenggarakan tugas-tugas umum pemerintahan maupun pembangunan terhadap segala aspek kegiatan masyarakat yang telah berpartisipasi dalam pelaksanaan pembangunan. ${ }^{26}$ Penyelenggara pelayanan publik bertugas untuk memenuhi kebutuhan penerima pelayanan yang pelaksanaannya dilakukan menurut ketentuan peraturan perundang-undangan. ${ }^{27}$ Pelayanan publik dilakukan oleh instansi pemerintah di pusat, di daerah dan di lingkungan Badan Usaha Milik Negara atau Badan Usaha Milik Daerah dalam segala bentuk jasa pelayanan untuk memenuhi kebutuhan masyarakat sesuai dengan aturan perundangundangan. ${ }^{28}$ Kualitas pelayanan atau standar pelayanan adalah ukuran yang telah ditentukan sebagai suatu pembakuan pelayanan yang baik termasuk pula baku mutu pelayanan. ${ }^{29}$ Keberhasilan pemerintah dalam menyelenggara pelayanan publik dapat menjadi indikator kepuasan masyarakat yang harus diperhatikan oleh penyedia pelayanan publik.

Terdapat keterkaitan antara pelayanan publik yang diterima oleh masyarakat dengan penerapan beban pajak daerah yang harus dibayarkan oleh masyarakat. Adapun beberapa kriteria mengenai pajak daerah, yaitu: ${ }^{30}$

a. Pungutan bersifat pajak dan bukan retribusi yang ditetapkan dalam undang-undang bersifat memaksa tanpa imbalan langsung, digunakan untuk membiayai penyelenggaraan pemerintahan dan pembangunan daerah.

Penjelasan mengenai poin pertama ini memperlihatkan bahwa pajak merupakan seuatu hal yang dapat dipaksakan kepada masyarakat. Implikasi yang terbentuk adanya daya paksa ini adalah warga dan masyarakat memiliki kewajiban untuk membayar pajak tepat waktu agar pemerintahan bisa berjalan dengan baik dan lancar. Walaupun rakyat tidak membayar kewajibannya, maka rakyat akan dikenakan hukuman denda karena tidak membayarkan kewajibannya sebagai warga negara. Kontraprestasi yang ada mengenai pajak tidak langsung dirasakan oleh rakyat. Maka dari itu poin tersebut menjelaskan bahwa pajak bersifat memaksa dan tidak terdapat imbalan langsung yang dirasakan.

b. Objek pajak terdapat di wilayah daerah kabupaten/kota yang bersangkutan dan hanya melayani masyarakat di wilayah tersebut.

Poin ini menjelaskan bahwa terdapat ruang lingkup yang membatasi adanya objek pajak yang dikenai pajak tersebut. Pelayanan tidak bisa dilakukan secara lintas daerah dan berbeda wilayah karena setiap institusi pelayanan publik memiliki kewenangan dan

\footnotetext{
${ }^{25}$ Ibid., 2.

26 Satriadi, "TINGKAT KEPUASAN MASYARAKAT PADA PELAYANAN PAJAK KENDARAAN BERMOTOR DI KANTOR SAMSAT TANJUNGPINANG", An-Nisbah 3, no. 2 (2017): 345-369, 346, DOI: 10.21274/an.2017.3.2.345-369.

${ }^{27}$ Keputusan Menteri Pendayagunaan Aparatur Negara Nomor. 63/KEP/M.PAN/7/2003 Tahun 2003 tentang Pedoman Umum Penyelenggaraan Pelayanan Publik, 2.

28 Nuriyanto, "PENYELENGGARA PELAYANAN PUBLIK DI INDONESIA, SUDAHKAN BERLANDASKAN KONSEP “WELFARE STATE”?”, Jurnal Konstitusi 11, no. 3 (2014): 428-453, 433, DOI: $10.31078 / \mathrm{jk} \% 25 \mathrm{x}$.

${ }^{29}$ Satriadi, Op.Cit., 346.

${ }^{30}$ Direktorat Jenderal Perimbangan Keuangan, "Pajak Daerah".
} 
yurisdiksinya masing-masing. Tentunya hal ini memiliki tujuan yang jelas. Data dari pemasukan pajak bisa lebih terkordinasi dengan baik dan tidak ada kesalahan dalam melakukan masukan/ input ke dalam sistem yang telah tersedia.

c. Objek dan dasar pengenaan pajak tidak bertentangan dengan kepentingan umum, tetap memperhatikan aspek ketentraman dan kestabilan politik, ekonomi, sosial, budaya serta pertahanan dan keamanan untuk kepentingan bersama.

Penjelasan dari poin tersebut adalah legal standing/atau dasar pengenaan pajak harus mengedepankan aspek kestabilan. Ketika kondisi perekonomian suatu negara sedang dalam kondisi sulit maka pemungutan pajak memang menjadi sesuatu kewajiban dan keharusan yang harus dipenuhi. Aspek penting dari poin ini ialah pajak bisa bersifat fleksibel dalam pelaksanaannya agar bisa menjaga adanya keadaan tertib di masyarakat.

d. Potensi pajak memadai dimana penerimaan hasil pajak harus lebih besar dari biaya pemungutan.

Aspek yang selanjutnya menjadi penting, karena akan sangat merugikan negara ketika biaya dari upaya pemungutan pajak lebih besar daripada hasil pajak yang didapatkan. Jangan sampai negara mengalami kerugian dalam hal yang berkaitan dengan pajak. Mengingat pajak merupakan salah satu sumber penting dari keuangan negara baik daerah maupun pusat. Seluruh elemen bersandar pada sektor pajak dalam hal penyelenggaraan pemerintahan.

e. Objek pajak tidak tumpang tindih dengan objek dan/atau dasar pengenaaan pajak lain yang hasilnya diterima oleh daerah yang bersangkutan.

Poin e menjelaskan bahwa tidak bisa terjadi disharmonisasi antara objek pajak tertentu dengan objek pajak lainnya karena hal ini akan menjadikan proses administrasi dari pajak akan mengalami masalah. Terdapat potensi terjadinya data ganda dalam sistem perpajakan jika tidak diperhatikan aspek mengenai hal tersebut.

f. Tidak memberikan dampak yang mengganggu alokasi sumber ekonomi antar daerah maupun kegiatan ekspor-impor.

Pajak memiliki tujuan untuk membantu sumber keuangan negara, bukan sebaliknya pajak bisa menjadi beban tambahan bagi negara dalam hal keuangan serta bisa menganggu kegiatan ekspor dan impor di suatu negara tersebut terkhusus negara Indonesia.

g. Memperhatikan kemampuan masyarakat dalam membayar pajak dilihat dari segi objek dan subjek pajak harus jelas, pemungutan dan jumlah pembayaran dapat diperkirakan oleh wajib pajak dan tarif pajak disesuaikan dengan kondisi wajib pajak.

Kedinamisan dalam hal pajak terlihat pada aspek ini, bahwa tarif pajak akan disesuaikan dengan adanya nilai dari kondisi wajib pajak. Pertimbangan dari sudut pandang yang menitikberatkan pada kondisi objek pajak dan subjek pajak akan bisa memberikan keadilan bagi masyarakat secara menyeluruh.

h. Aspek kemampuan masyarakat dalam membayar pajak sehingga masyarakat yang relatif kurang mampu tidak memikul sebagian besar dari tambahan beban pajak.

Proporsionalitas dan keadilan harus tetap hadir dalam proses pemungutan dan pengambilan pajak. Tidak semua masyarakat memiliki kondisi perekonomian yang sama. Terdapat masyarakat kurang mampu, dan ada masyarakat dengan kelebihan dalam hal keuangan. Aspek ini menjadi sangat berguna untuk menghadirkan nilai-nilai keadilan dan kebermanfaatan dari pajak tersebut.

i. Tidak memberikan peluang kepada daerah atau pusat atau masyarakat untuk merusak lingkungan dalam pelaksanaan pajak sebagai bentuk menjaga kelestarian lingkungan.

Selain adanya aspek proporsionalitas dan aspek keadilan, dalam pemungutan pajak tentu harus memperhatikan aspek dan kondisi lingkungan. Lingkungan harus tetap terjaga karena lingkungan menjadi sangat penting untuk keberlangsungan dari kehidupan yang akan datang. 
Pelayanan yang dimaksudkan adalah pelayanan yang diberikan secara langsung kepada masyarakat oleh pemerintah berdasarkan penerimaan pajak daerah sesuai dengan sektor pajak daerah yang bersangkutan. ${ }^{31}$ Buku yang berjudul "Potret Pajak Daerah di Indonesia" karangan Tjip Ismail menggunakan dua parameter untuk menentukan standar parameter pelayanan yaitu parameter yang diperoleh dari Dispenda DKI berdasarkan wujud dari pelayanan yang telah dilaksanakan selama ini oleh Pemda DKI Jakarta (disebut parameter formal) dan parameter yang didasarkan pada pemikiran Tjip Ismal selaku penulis dalam bukunya tersebut (disebut parameter ideal). ${ }^{32}$ Kedua parameter tersebut merupakan standar bagi wujud pelayanan pemerintah daerah sebagai bentuk kontraprestasi bagi sektor pajak yang dipungut apakah pelayanan yang diberikan oleh pemerintah telah sesuai dengan beban pajak yang dibayarkan oleh masyarakat.

\section{Beban Pajak Daerah dan Pelayanan yang Diberikan Kepada Masyarakat}

Ciri-ciri dari pajak daerah dengan PPN semiliki kesamaan, berkaitan dengan hal tesebut masalah pengenaan pajak atas konsumsi masyarakat, terdapat perbedaan fundamental dalam menentukan adanya objek pajak. Objek PPN memiliki sifat yaitu negative list, hal tersebut memiliki makna bahwa seluruh penyerahan barang dan jasa yang tidak dikecualikan dalam peraturan perundang-undangan merupakan objek PPN. ${ }^{33}$ Berdasarkan pengatur yang tercantum dalam Pasal 4A Undang-undang Nomor 42 tahun 2009, maka jenis barang yang tidak dikenai PPN adalah barang tertentu dalam kelompok barang hasil pertambangan atau hasil pengeboran yang diambil langsung dari sumbernya; barang kebutuhan pokok yang sangat dibutuhkan oleh rakyat banyak; makanan dan minuman yang disajikan di hotel, restoran, rumah makan, warung, dan sejenisnya, meliputi makanan dan minuman baik yang dikonsumsi di tempat maupun tidak, termasuk makanan dan minuman yang diserahkan oleh usaha jasa boga atau katering; dan uang, emas batangan, dan surat berharga.

Terdapat jenis jasa yang tidak dikenakan PPN adalah adapaun jasa tertentu dalam kelompok jasa pelayanan kesehatan medis, jasa pelayanan sosial, jasa pengiriman surat dengan perangko, jasa keuangan, jasa asuransi, jasa keagamaan, jasa pendidikan, jasa kesenian dan hiburan, jasa penyiaran yang tidak bersifat iklan, jasa angkutan umum di darat dan di air serta jasa angkutan udara, jasa-jasa tersebut merupakan mencakup wilayah dalam negeri yang menjadi bagian yang tidak terpisahkan dari jasa angkutan udara luar negeri, jasa tenaga kerja, jasa perhotelan, jasa yang alokasikan oleh pemerintah dalam agenda untuk mengimplementasikan pemerintahan secara umum, jasa penyediaan tempat parkir, jasa jasa telepon umum dengan menggunakan uang logam, jasa pengiriman uang dengan wesel pos dan jasa boga atau katering. Adapun terdapat objek pajak daerah yang memiliki karakteristik positive list, sifat tersebut akan memberikan dampak yang siginifikan, yang berarti bahwa segala jenis objek pajak menjadi objek Pajak Daerah harus tercantum dalam UU PDRD. Kebijakan yang diterapkan berdasarkan UU PPN dan UU PDRD secara tidak langsung meregulasi bahwa pajak atas konsumsi yang menjadi objek PPN merupakan hak pemerintah pusat sedangkan pemerintah daerah diberikan otoritas untuk mengutip sebagian kecil wilayah objek PPN sebagai sumber pendapatan asli daerah.

Terfokus pada pajak daerah merupakan sumber dana yang bisa mewujudkan adanya pendapatan asli daerah dilaksanakan secara optimal. Pendapatan daerah yang didapat melalui pajak daerah diperuntukan untuk belanja daerah, serta keperluan lain yang diperlukan oleh

\footnotetext{
31 Tjip Ismail, Op.Cit., 47.

${ }^{32}$ Lihat pada Tabel Parameter Formal Wujud Pelayanan dan Tabel Parameter Ideal Wujud Pelayanan dalam bukum "Potret Pajak Daerah di Indonesia" karangan Tjip Ismail, 47-53.

33 Benny Gunawan Ardiansyah, "IMPLIKASI PUTUSAN MAHKAMAH KONSTITUSI", Jurnal Pajak Indonesia 1, no. 1 (2018): 56-67, 58.
} 
daerah tersebut. Adanya keterkaitan antara pajak daerah dengan dana alokasi anggaran bisa memberikan efek yang berkesinambungan dalam menjalankan dan mengimplementasikan birokrasi pemerintahan terkhusus yang ada di daerah. ${ }^{34}$ Betapa pentingnya Pajak daerah sangat menentukan adanya kualitas pelayanan publik yang akan diberikan kepada masyarakat umum.

Menurut Black's Law Dictionary, dalam pengertian umum, pajak adalah setiap kontribusi yang dibebankan oleh pemerintah kepada individu, untuk penggunaan dan pelayanan negara, baik itu tol, upeti, jangkauan, pungutan, bea, bea cukai, subsidi, bantuan, suplai atau nama lainpa. Berdasarkan definisi tersebut memperlihatkan bahwa pajak memiliki berbagai ragam dan jenis. Terdapat pajak bea, pajak subsidi, pajak tol dan masih banyak lagi. Peruntukan pajak sudah sangat jelas diterangkan melalui definisi tersebut bahwa pajak pada sejatinya ditujukan untuk menjadi sumber keuangan dari pelayanan publik kepada masyarakat.

Penerapan adanya konsep otonomi daerah memberikan implikasi bahwa pemerintah daerah berwenang membuat kebijakan penerimaan pajak terutama yang berasal dari PAD. Hal tersebut diharapkan dapat memperkuat proyek pembangunan dan penyelenggaraan pemerintah daerah. Menurut Pasal 1 Angka 10 Undang-Undang Nomor 28 Tahun 2009 tentang Pajak Daerah dan Retribusi Daerah (selanjutnya disebut UU No. 28 Tahun 2009) menjelaskan bahwa pajak daerah adalah kontribusi wajib oleh orang pribadi atau badan yang digunakan untuk keperluan daerah bagi kemakmuran rakyat yang bersifat memaksa dan berdasarkan undang-undang. ${ }^{35}$ Perbedaan mendasar pajak dan pajak daerah hanya terletak pada wilayah yang mencakup adanya pemungutan pajak tersebut.

UU No. 28 Tahun 2009 membagi pajak daerah ke dalam dua jenis pajak yakni pajak provinsi dan pajak kabupaten/kota. Pajak provinsi yang terdiri dari 5 sektor perpajakan dan pajak kabupaten/kota terdiri dari 11 sektor perpajakan yang semuanya dijabbarkan pada Pasal 2 UU tersebut. Terdapat beberapa kriteria dalam mempertimbangkan pemungutan suatu pajak daerah agar memenuhi unsur-unsur keadilan. ${ }^{36}$ Kriteria memilih pajak daerah dapat didasarkan oleh beberapa hal sebagai berikut: ${ }^{37}$

a. Kecukupan: hasil pajak dengan pengeluaran yang dikenakan harus sesuai;

b. Kepastian dan dapat diprediksi: hasil pajak tidak mengalami gejala perubahan yang besar setiap tahunnya;

c. Elastisitas: hasil dari pajak dapat mengikuti perkembangan inflasi, pertumbuhan populasi dan peningkatan pendapatan;

d. Biaya pemungutan: perbandingan sekecil mungkin antara biaya pemungutan dan hasil pajak.

Kemudian, terdapat beberapa aspek yang dipertimbangkan terkait dengan keadilan antara beban pajak dan kemampuan membayar pajak, antara lain: ${ }^{38}$

a. Tidak sembarangan: nominal pajak yang dikenakan kepada pembayar pajak dan kewajiban membayar harus diatur dengan jelas dan tidak sulit dipahami;

b. Prinsip manfaat: penerima manfaat atas pelayanan pemerintah harus memberikan kontribus atas pelayanan tersebut;

\footnotetext{
${ }^{34}$ Ilyas Ismail, Mahdi Syahbandir, "PERANAN PAJAK BEA PEROLEHAN HAK ATAS TANAH DAN BANGUNAN UNTUK MENINGKATKAN PENDAPATAN ASLI DAERAH KABUPATEN PIDIE," Kanun: Jurnal Ilmu Hukum 18, no. 2 (2016): 299-318, 300, DOI: 10.24815/kanun.v18i2.5912.

${ }^{35}$ Jonetta T, "KONTRIBUSI PAJAK DAERAH DAN RETRIBUSI DAERAH TERHADAP PENDAPATAN ASLI DAERAH DALAM RANGKA PELAKSANAAN OTONOMI DAERAH KOTA SAMARINDA", Jurnal Ekonomia 5, no. 3 (2016): 364-376, 364.

${ }^{36}$ Direktorat Jenderal Perimbangan Keuangan, "Pajak Daerah".

${ }^{37}$ Ibid.

${ }^{38} \mathrm{Ibid}$.
} 
c. Keadilan horizontal: kesetaraan antara orang-orang dalam lingkungan ekonomi yang sama untuk diperlakukan dengan cara yang sama;

d. Keadilan vertikal: perpajakan harus proporsional dimana beban pajak dengan kemampuat untuk membayar pajak disesuaikan untuk memenuhi keadilan.

Fungsi pajak daerah tidak hanya untuk mengisi kas daerah (APBD) namun juga pemberian pelayanan oleh pemerintah kepada rakyatnya sebagai tujuan otonomi daerah. ${ }^{39}$ Dalam hal ini, fungsi budgeter merupakan fungsi pajak sebagai pengisi kas daerah. Namun, fungsi regulenrend atau mengatu merupakan fungsi yang memaknai otonomi daerah yang dalam hal ini berkaitan dengan upaya-upaya pelayanan. ${ }^{40}$ Diikuti dengan diterbitkannya Undang-Undang Nomor 9 Tahun 2015 tentang Perubahan Kedua Atas Undang-Undang Nomor 23 Tahun 2014 tentang Pemerintahan Daerah yang menitikberatkan pada pelayanan kepada masyarakat sebagaimana tercantum pada bagian menimbang huruf a undang-undang tersebut. Terdapat pergeseran paradigma mengenai pajak daerah dimana pemerintah memberikan kontraprestasi dalam bentuk pelayanan kepada masyarakat. Kontrapestasi tersebut disesuaikan dengan peruntukannya yang diatur di dalam undang-undang dan peraturan pelaksanaannya untuk mencapai kepastian berkaitan dengan kewajiban kontraprestasi dalam memberikan pelayanan yang sesuai dengan jenis pajak yang perhitungannya telah dialokasikan oleh pemerintah daerah. ${ }^{41}$ Konsep umum tersebut adalah sebagai berikut: ${ }^{42}$

a. Pajak Kendaraan Bermootor dan Bea Balik Nama Kendaraan Bermotor

Hasil pajak kendaraan bermotor dan bea balik nama kendaraan bermotor seharusnya digunakan untuk perbaikan jalan, perbaikan rambu-rambu jalan, penyelenggaraan fasilitas keamanan dan pegamanan bagi pengendara kendaraan bermotor dan kendaraan di atas pembuatan dermaga/pelabuhan, terminal dan sarana prasarana lainnya seperti tempat pengisian bahan bakar bagi kendaraan bermotor.

b. Pajak Bahan Bakar Kendaraan Bermotor (PBB-KB)

PBB-KB dibayarkan oleh orang pribadi atau badan yang mengunakan bahan bakar bermotor. Pembayar pajak tersebut berhak untuk mendapatkan sarana dan prasarana yang berkaitan dengan pengawasan kualitas dan harga jual bahan bakar serta pengendalian dampaknya terhadap lingkungan.

c. Pajak Pengambilan dan Pemanfaatan Air Permukaan

Pajak ini digunakan oleh pemerintah daerah untuk melakukan pemeliharaan dan pengawasan ekosistem air permukaan baik secara kualitas ataupun kuantitas dengan cara melakukan pengawasan dan pemeliharaan saluran-saluran air, sungai, bantaran sungai, irigasi dan sebagainya.

d. Pajak Rokok

Penerimaan pajak rokok yang diterapkan di provinsi maupun kabupaten/kota digunakan untuk kepentingan pelayanan kesehatan masyarakat.

e. Pajak Hotel dan Pajak Restoran

Pajak hotel dan pajak restoran digunakan untuk pengamanan dan kenyamanan tamu-tamu dengan memberikan fasilitas-fasilitas yang memadai.

f. Pajak Hiburan

Pajak hiburan tidak jauh berbeda dengan pajak hotel dan pajak restoran yang peruntukannya adalah memprasaranai semua bentuk hiburan yang berkaitan dengan pengusaha hiburan dan masyarakat luas.

\footnotetext{
${ }^{39}$ Tjip Ismail, Potret Pajak Daerah di Indonesia, 139.

${ }^{40}$ Ibid.

${ }^{41}$ Ibid., 145.

${ }^{42}$ Ibid., 145-150.
} 
g. Pajak Reklame

Penerimaan pajak reklame ini harus digunakan oleh pemerintah daerah untuk melakukan pengawasan, penertiban dan pemeliharaan sarana dan prasarana yang berkaitan dengan reklame ini termasuk berkaitan dengan mengawasi materi muatan reklame yang bersangkutan, mengawasi keamanan serta keindahan letaknya.

h. Pajak Penerangan Jalan

Pemerintah daerah diharapkan dapat menjamin suplai listrik dengan baik dan menjamin tersedianya sarana dan prasarana penerangan jalan yang memadai di daerahnya.

i. Pajak Mineral Bukan Logam dan Batuan

Selain digunakan oleh pemerintah daerah untuk menyediakan sarana dan prasarana keperluan pengusaha, pajak ini juga digunakan untuk kepentingan aspek lingkungan seperti penentuan standar kualitas dan pengawasan standar kualitas untuk menanggulangi pencemaran lingkungan dan polusi.

j. Pajak Parkir

Pajak parkir ini pada dasarnya digunakan untuk penertiban perparkiran di sekitar kawasan pengusaha pengelola parkir agar masyarakat dapat menggunakan jasa perpakiran dengan aman.

k. Pajak Air Tanah

Pengambilan air tanah akan berakibat pada terjadinya kerusakan rawan berupa erosi, kekeringan dan lain-lain. Untuk itu diperlukan biaya untuk rehabilitasi dan reklamasi akibat eksplorasi dan ekploitasi air tanah dimana biaya tersebut diambil dari pajak air tanah.

1. Pajak Sarang Burung Walet

Pajak ini diambil untuk melakukan pencegahan melalui pemajakan sarang burung walet dan diharapkan juga dapat digunakan untuk menjaga kelestarian alam.

m. PBB Perdesaan/Perkotaan dan BPHTB

Hasil penerimaan pajak PBB dan BPHTB diprioritaskan untuk memperbaiki tata ruang dalam membangun dan mengembangkan otonomi daerah di kabupaten/kota.

Setidaknya ada tiga belas pajak yang bisa dijadikan sumber pendanaan daerah dalam menjalankan roda pemerintahan. Semua pajak-pajak tersebut harus bisa dimanfaatkan secara bijak dan baik oleh pemerintah untuk keperluan yang strategis. ${ }^{43}$

Semua konsep wujud pelayanan pemerintah daerah kepada masyarakat di atas, tidak akan dapat dilaksanakan apabila tidak didukung oleh pemahaman hakikat pajak daerah dan kesungguhan aparatur pemerintah daerah dalam pelaksanaannya. Otonomi daerah memberikan kewenangan dalam penyerahan pelayanan dari pemerintah pusat kepada pemerintah daerah agar menjangkau masyarakat secara nyata. ${ }^{44}$ Meskipun demikian, di dalam penerapannya, terdapat permasalahan ketika merancang sistem pajak yang adil dikarenakan oleh: ${ }^{45}$

a. Jumlah masyarakat yang memiliki penghasilan yang cukup lebih kecil dibanding masyarakat kurang mampu sehingga golongan masyarakat menengah ke bawah juga dikenakan pajak dikarenakan tingkat rata-rata pajak rendah;

b. Data yang kurang akurat mengenai pengenaan pajak;

c. Ketidak-akuratan penilaian yang merugikan masyarakat miskin;

d. Pertumbuhan ekonomi yang terdampak oleh pajak progresif.

\footnotetext{
${ }^{43}$ Rini Irianti Sundary, "PENGALIHAN BEA PEROLEHAN HAK ATAS TANAH DAN BANGUNAN DARI PAJAK PUSAT MENJADI PAJAK DAERAH SEBAGAI UPAYA PENINGKATAN PENDAPATAN ASLI DAERAH", Jurnal Aktualita 1, no.1 (2018) : 279-294, 280, DOI: 10.29313/aktualita.v1i1.3723.

${ }^{44}$ Ibid., 150.

45 Direktorat Jenderal Perimbangan Keuangan, "Pajak Daerah”.
} 


\section{Kesimpulan}

Berdasarkan pembahasan di atas, maka dapat disimpulkan bahwa pajak daerah memiliki beberapa kriteria dalam memungut pajak yaitu pungutan bersifat pajak dan bukan retribusi dimana objeknya terletak di wilayah daerah yang bersangkutan, dasar pengenaan pajak tidak bertentangan dengan kepentingan umum, potensi pajak memadai, objek pajak merupakan objek yang terlepas dari pajak pusat, tidak memberikan dampak ekonomi yang negatif, mempertimbangkan kemampuan masyarakat untuk memenuhi aspek keadilan serta menjaga kelestarian lingkungan. Terdapat beberapa kriteria dalam mempertimbangkan pemungutan suatu pajak daerah dengan memperkirakan perolehan dan pemenuhan unsur-unsur keadilan seperti kecukupan, kepastian dan dapat diprediksi, elastisitas, dan biaya pemungutan. Terdapat pergeseran paradigma mengenai pajak daerah dimana pemerintah memberikan kontaprestasi dalam bentuk pelayanan kepada masyarakat. Kontrapestasi tersebut harus sesuai dengan penggunaannya dan ditentukan oleh undang-undang maupun peraturan pelaksanaannya. Meskipun demikian, dalam penerapannya, masih terdapat permasalahan ketika merancang sistem pajak yang adil.

Dalam hal ini penulis akan menyarankan adanya variasi terhadap beban pajak secara sistematis dan terukur agar dapat mengakomodir berbagai macam situasi. Efektivitas dan efisiensi ekonomi tergantung dari pajak-pajak tertentu pada keputusan untuk mengonsumsi, menabung, bekerja dan berinvestasi. Terjadinya perubahan paradigma pajak daerah dari sisi pemerintah daerah dapat meningkatkan kesadaran para wajib pajak untuk membayar pajak apabila wajib pajak merasakan manfaat pembayaran pajak bagi dirinya dan masyarakat luas melalui pelayanan pemerintah daerah.

\section{A. Jurnal}

\section{DAFTAR PUSTAKA}

Adiyanta, F.C. Susila. "KARAKTERISTIK RESPONSIF PERATURAN DAERAH TENTANG PAJAK-PAJAK DAERAH SEBAGAI REPRESENTASI DAN PARTISIPASI KEHENDAK PUBLIK". Administrative Law \& Government Journal 2, no. 2, 2019: 380-399, DOI: 10.14710/alj.v2i3.380\%20-\%20399.

Ardiansyah, Benny Gunawan. "IMPLIKASI PUTUSAN MAHKAMAH KONSTITUSI", Jurnal Pajak Indonesia 1, no. 1, 2018: 56-67.

Bawazier, Fuad. "REFORMASI PAJAK DI INDONESIA,” Jurnal Legislasi Indonesia 8, no. 1, 2018: 1-12.

Ismail, Ilyas., Syahbandir, Mahdi. "PERANAN PAJAK BEA PEROLEHAN HAK ATAS TANAH DAN BANGUNAN UNTUK MENINGKATKAN PENDAPATAN ASLI DAERAH KABUPATEN PIDIE," Kanun: Jurnal Ilmu Hukum 18, no. 2, 2016: 299318, DOI: 10.24815/kanun.v18i2.5912.

Lamia, Alfan A., Saerang, David P. E., Wokas, Heince R. N. "ANALISIS EFEKTIFITAS DAN KONTRIBUSI PEMUNGUTAN THE ANALYSIS OF EFECTIVENESS AND CONTRIBUTION RECEIPTS TAX RESTAURANT , ADVERTISING TAX AND STREET LIGHTING LEVY DISTRICT," Jurnal Berkala Ilmiah Efisiensi 15, no. 05, 2015: 788-799.

Maryam, Neneng Siti. "MEWUJUDKAN GOOD GOVERNANCE MELALUI PELAYANAN PUBLIK," Jurnal Ilmu Politik dan Komunikasi 5, no. 1, 2017.

Nuriyanto. "PENYELENGGARA PELAYANAN PUBLIK DI INDONESIA, SUDAHKAN BERLANDASKAN KONSEP “WELFARE STATE”?". Jurnal Konstitusi 11, no. 3, 2014: 428-453, DOI: $10.31078 / \mathrm{jk} \% 25 x$.

Oktavina, Dewi. "ANALISIS PENDAPATAN ASLI DAERAH DAN FAKTOR-FAKTOR YANG MEMPENGARUHINYA DALAM RANGKA OTONOMI DAERAH: 
PENDEKATAN ERROR CORRECTION MODEL", JEPE: Jurnal Ekonomi Pembangunan 10, no. 2, 2012: 89-101, DOI: 10.22219/jep.v10i2.3720.

Pertiwi, Rizka Novianti., Azizah, Devi Farah., Kurniawan, Bondan Catur. "ANALISIS EFEKTIVITAS PEMUNGUTAN PAJAK BUMI DAN BANGUNAN (STUDI PADA DINAS PENDAPATAN, PENGELOLAAN KEUANGAN DAN ASET KOTA PROBOLIGGO)". Jurnal Perpajakan 3, no. 1, 2014: 1-7.

Satriadi. "TINGKAT KEPUASAN MASYARAKAT PADA PELAYANAN PAJAK KENDARAAN BERMOTOR DI KANTOR SAMSAT TANJUNGPINANG”. AnNisbah 3, no. 2, 2017: 345-369, DOI: 10.21274/an.2017.3.2.345-369.

Siahaan, Sentosa., Lodewyk, Albert. "KAJIANYURIDIS TERHADAP BERALIHNYA KEWENANGAN PEMUNGUTAN PAJAK BUMI DAN BANGUNAN PERDESAAN DAN PERKOTAAN DARI PEMERINTAH PUSAT KEPADA PEMERINTAH DAERAH KABUPATEN SERDANG BEDAGAI." Premise Law Journal 8, 2015: 1-16.

Sulastyawati, Dwi. "HUKUM PAJAK DAN IMPLEMENTASINYA BAGI KESEJAHTERAAN RAKYAT”. Jurnal Filsafat dan Budaya Hukum 1, no. 1, 2014: 119-128, DOI: 10.15408/sjsbs.v1i1.1530.

Suliantoro, Adi. "KAJIAN TERHADAP UU NO. 28 TAHUN 2007 TENTANG KETENTUAN UMUM DAN TATA CARA PERPAJAKAN", Fokus Ekonomi (FE) 7, no. 1, 2008: 36-43.

Sundary, Rini Irianti. "PENGALIHAN BEA PEROLEHAN HAK ATAS TANAH DAN BANGUNAN DARI PAJAK PUSAT MENJADI PAJAK DAERAH SEBAGAI UPAYA PENINGKATAN PENDAPATAN ASLI DAERAH", Jurnal Aktualita 1, no.1, 2018: 279-294, DOI: 10.29313/aktualita.v1i1.3723.

T, Jonetta. "KONTRIBUSI PAJAK DAERAH DAN RETRIBUSI DAERAH TERHADAP PENDAPATAN ASLI DAERAH DALAM RANGKA PELAKSANAAN OTONOMI DAERAH KOTA SAMARINDA." Jurnal Ilmu Hukum Riau 5, no. 3, 2016: 364-376.

Wokas, Heince R., Kobandaha, Rezlyanti. "ANALISIS EFEKTIVITAS, KONTRIBUSI DAN POTENSI PAJAK REKLAME DAN PAJAK HOTEL TERHADAP PENDAPATAN ASLI DAERAH KOTA KOTAMOBAGU," Jurnal Riset Ekonomi, Manajemen, Bisnis Dan Akuntansi 4, no. 1, 2016: 1461-1472, $\quad$ DOI: 10.35794/emba.v4i1.12366.

\section{B. Buku}

Abuyamin, Oyok. Perpajakan. Bandung: Mega Rancager Press, 2016.

Brotodihardjo, R. Santoso. Pengantar Ilmu Hukum Pajak. Bandung: ERESCO, 1993.

Ibrahim, Johnny. Teori dan Metodologi Penelitian Hukum Normatif. Surabaya: Bayu Media Publishing. 2005.

Ismail, Tjip. Potret Pajak Daerah di Indonesia. Jakarta: Prenadamedia, 2018.

Soekanto, Soerjono dan Sri Mamudji. Penelitian Hukum Normatif 13. Jakarta: Raja Grafiondo Persada, 2000.

\section{Peraturan Perundang-Undangan}

Keputusan Menteri Pendayagunaan Aparatur Negara Nomor 63/KEP/M.PAN/7/2003 tentang Pedoman Umum Penyelenggaraan Pelayanan Publik

Undang-Undang Dasar Republik Indonesia Tahun 1945.

Undang-Undang Repbulik Indonesia Nomor 9 Tahun 2015 tentang Perubahan Kedua Atas Undang-Undang Nomor 23 Tahun 2014 tentang Pemerintahan Daerah

Undang-Undang Republik Indonesia Nomor 28 Tahun 2007 tentang Ketentuan Umum dan Tata Cara Perpajakan. 
Undang-Undang Republik Indonesia Nomor 28 Tahun 2009 tentang Pajak Daerah dan Retribusi Daerah

\section{Internet}

https://www.pajakku.com/read/5d9ee689b01c4b456747b6d2/Pajak-dari-oleh-dan-untukRakyat, diakses 29 Maret 2020.

https://bprd.jakarta.go.id/2016/10/10/pajak-daerah-bukan-pajak-pusat/, diakses 29 Maret 2020.

http://www.djpk.kemenkeu.go.id/wp-content/uploads/2018/08/pajak_daerah-1.pdf, diakses 29 Maret 2020. 